\title{
Análise histórica da severidade de secas no Ceará: efeitos da aquisição de capital hidráulico sobre a sociedade
}

\author{
Historical analysis of the severity of droughts in Ceará: \\ effects of the acquisition of hydraulic capital on society
}

\begin{abstract}
Luiz Fabiano Camilo Viana Nunes ${ }^{1}$, Pedro Henrique Augusto Medeiros ${ }^{1}$ [C]
${ }^{1}$ Instituto Federal de Educação, Ciência e Tecnologia do Ceará, Maracanaú, CE, Brasil. E-mails: contraagravidade@hotmail.com,phamedeiros@ifce.edu.br
\end{abstract}

Como citar: Nunes, L. F. C. V., \& Medeiros, P. H. A. (2020). Análise histórica da severidade de secas no Ceará: efeitos da aquisição de capital hidráulico sobre a sociedade. Revista de Gestão de Água da América Latina, 17, e18. https://doi.org/10.21168/rega.v17e18

RESUMO: Neste estudo, realizou-se uma análise histórica das secas no Ceará entre os anos de 1912 e 2018, buscando-se a compreensão dos efeitos desse fenômeno sobre a sociedade. Para a quantificação da severidade das secas, utilizou-se o Índice de Porcentagem Normal (IPN), contrapondo-o à evolução da aquisição de capital hidráulico, caracterizada pela construção de açudes e indicativa da disponibilidade de água, e ao crescimento populacional, indicativo da demanda hídrica. A análise da capacidade de convívio com a escassez hídrica indica que, apesar dos efeitos positivos da aquisição de capital hidráulico, os benefícios se concentraram nos grandes sistemas consumidores de água. Por exemplo, na seca de 2012 a 2017 não houve desabastecimento da Região Metropolitana de Fortaleza, enquanto cidades menores e comunidades rurais enfrentaram problema de escassez., o que pode ser constatado pelas elevadas quantias gastas com operação carro-pipa. 0 grande desafio parece ser a distribuição do bônus do capital hidráulico para toda a sociedade cearense.

Palavras-chave: Escassez Hídrica, Severidade de Secas; Capital Hidráulico; Convivência com Secas.

ABSTRACT: In this study, a historical analysis of the droughts in Ceará between the years of 1912 and 2018 was carried out, aiming to understand the effects of this phenomenon on the society. For the quantification of drought severity, the Index of Percentage of Normal precipitation (IPN) was used, contrasting it with the evolution of the acquisition of hydraulic capital, characterized by the construction of dams and indicative of water availability, and with the population growth, indicative of the water demand. The analysis of the adaptation capacity to water scarcity indicates that, despite the positive effects of the acquisition of hydraulic capital, the benefits were concentrated in the large water consuming systems. For example, in the drought of 2012 to 2017, there was no failure on the supply of the Fortaleza Metropolitan Region, whereas smaller cities and rural communities faced shortage, which can be observed from the high amounts spent on water trucks. The great challenge seems to be the distribution of the hydraulic capital bonus to the entire Ceará society.

Keywords: Water scarcity; Severity of Drought; Hydraulic Capital; Co-existence with Droughts.

\section{INTRODUÇÃO}

Quando questionados sobre a gênese da civilização, autores das diversas áreas do conhecimento podem, por exemplo, divergir entre a importância da escrita ou da agricultura como marco civilizatório. Contudo, uma vez que as primeiras civilizações se firmaram em torno da água, diante do olhar da engenharia, a hidráulica é o marco civilizatório. Neste contexto, as obras hidráulicas foram fundamentais para o desenvolvimento de assentamentos humanos em locais privilegiados da geografia terrestre, como no Egito Antigo e na Mesopotâmia, mesmo quando as cheias do rio Nilo ou o degelo das montanhas na primavera, respectivamente, desafiaram a inventividade humana.

Ao investigar a aquisição do capital hidráulico cearense, observa-se a transição civilizatória de uma sociedade das chuvas, onde a total dependência meteorológica é evidente, para uma sociedade hidráulica, marcada pela construção de açudes para armazenamento da água nos períodos de elevada precipitação, tendo em vista o suprimento hídrico nos períodos de escassez. Como se trata de uma

Recebido: Junho 10, 2020. Revisado: Agosto 11, 2020. Aceito: Setembro 09, 2020. 
área semiárida, com precipitação anual variando de 500 a pouco mais de $1000 \mathrm{~mm}$ concentrada de janeiro a maio (mais de $80 \%$ do total anual), e atualmente com porções desertificadas, a sociedade cearense teve, ao longo de sua história, um diálogo constante com a seca.

O entendimento da seca como fenômeno meteorológico característico do semiárido do Nordeste do Brasil se deu ao longo de séculos e passou por momentos de negação, aceitação, combate e, por fim, convívio. Investigar a aquisição do capital hidráulico por essa sociedade exige, portanto, a compreensão da seca em uma perspectiva histórica, possibilitando a avaliação dos efeitos da abordagem tecnológica adotada sobre o ambiente e as atividades humanas. Ademais, a compreensão da seca sob a perspectiva da sua interação com o ambiente e a sociedade, contribui para a análise da abordagem política da seca, e a forma com que o governo encara a seca traz consequências para o povo. Uma compreensão afinada com as indicações elaboradas por técnicos, observando o estado da arte do conhecimento técnico-científico, tende a produzir efeitos positivos para o convívio da crescente população com o semiárido. Por outro lado, as decisões desafinadas do governo, ou mesmo inércia diante da seca, potencializam os efeitos danosos à população cearense.

Este trabalho foi motivado pela seca de 2012-2017, período que compreende o centenário da seca histórica de 1915, quando se questionou qual teria sido o evento mais desastroso, 1915 ou a seca de 2012-2017. A favor de 1915, há diversos registros sobre como a seca atingiu a sociedade cearense, o desmantelo do seu processo produtivo, as perdas econômicas e humanas. Mas qual era a intensidade da seca de 1915 e a do evento mais recente? O que seria mais impactante: um ano de seca extrema ou uma sequência de anos secos, mesmo em se tratando de seca moderada? Para buscar estas respostas eram necessários índices capazes de promover a classificação da intensidade das secas e, também, diante da perspectiva histórica, avaliar como o desenvolvimento do capital hidráulico cearense afetou o convívio com as secas. Contudo, diante das lacunas de informação existente, eram ainda necessários dados com uma cronologia centenária. Além da comprovação histórica para efetivação da sua validade, os índices deveriam permitir a avaliação das consequências da abordagem tecnológica adotada, representada aqui pela crescente capacidade de acúmulo de água advinda da construção de açudes, como solução hidráulica. Por fim, quando associada aos dados relacionados à demanda, ilustrada pelo crescimento populacional, a leitura dos índices de seca e do crescimento da capacidade hídrica, representada pela açudagem, explicitou as consequências da abordagem política da seca. Assim, para avaliar se, e de que maneira, a aquisição de capital hidráulico foi capaz de aliviar os efeitos das secas no período de 1912 a 2018 na sociedade cearense, considerando-se os diferentes setores usuários de água, procedeu-se a análise histórica da evolução do capital hidráulico, utilizando-se como referência: o Índice de Porcentagem Normal (IPN) de precipitação, a capacidade de acumulação dos açudes e os dados censitários da população cearense.

\section{O QUE É A SECA?}

No Brasil, a região semiárida tem área de aproximadamente um milhão de $\mathrm{km}^{2}$ e uma população superior a 20 milhões de habitantes (de Araújo \& Bronstert, 2016), sendo uma das áreas semiáridas mais densamente povoadas no mundo e onde as secas são recorrentes. Poucos eventos extremos são tão economicamente e ecologicamente perturbadores quanto a seca, que afeta milhões de pessoas no mundo a cada ano (Wilhite, 2000). O estudo desse evento climático requer a compreensão das classificações de secas, que se relacionam com o modo como as mesmas atingem uma região.

Diversas são as classificações sobre secas (Mishra \& Singh, 2010), sendo aqui adotada a seguinte classificação proposta por Fernandes et al. (2009):

- Seca Meteorológica é expressa apenas com base no grau de secura e na duração do período seco comparados a algum estado "normal”, ou seja, é caracterizada pelo déficit de precipitação em relação ao valor normal. Caracteriza-se pela falta de água induzida pelo desequilíbrio entre a precipitação e a evaporação, a qual depende de outros elementos como a velocidade do vento, temperatura, umidade do ar e insolação.

- Seca Agrícola está associada à disponibilidade de água no solo para suportar o crescimento e desenvolvimento das plantas. A umidade deficiente no solo junto à cultura pode afetar a germinação, o crescimento e o desenvolvimento da planta, conduzindo à redução do rendimento final da atividade agrícola.

- Seca Hidrológica está relacionada com a redução dos níveis médios de água em reservatórios superficiais e subterrâneos por um determinado período de tempo, podendo ser de dias, semanas, meses ou anos sucessivos. Portanto, a seca hidrológica afeta o abastecimento hídrico da sociedade. 
- Seca Socioeconômica está relacionada com o impacto da seca sobre as atividades humanas, incluindo os impactos diretos e indiretos na produção agrícola e outras atividades econômicas. Ocorre quando o déficit de água induz a falta de bens ou serviços (energia elétrica, alimentos, entre outros) devido a um volume de água inadequado, resultante de má distribuição das chuvas, de um aumento no consumo, e/ou ainda de um mau gerenciamento dos recursos hídricos.

Portanto, a seca pode ser registrada meteorologicamente sem, no entanto, trazer qualquer consequência para o abastecimento, se contar com reserva suficiente de anos anteriores. Da mesma forma, para o fim de uma seca socioeconômica, pode não ser suficiente uma quadra chuvosa acima da média histórica, já que a economia pode apresentar um ritmo de recuperação distinto da meteorologia. Semelhante às classificações, as definições de seca são diversas e evoluíram historicamente, vejamos algumas:

- $\quad$ Guerra (1981) afirma que seca consiste na falta ou má distribuição das chuvas;

- $\quad$ A Convenção das Nações Unidas de Combate à Desertificação (UN Secretariat General, 1994) define seca como o fenômeno natural que existe quando a precipitação tem sido significativamente abaixo dos níveis normais registrados, causando sérios desequilíbrios hidrológicos que afetam adversamente os sistemas de produção de recursos;

- A enciclopédia do clima e do tempo (Schneider, 1996) define seca como um período prolongado - uma estação, um ano, ou vários anos - de precipitação deficiente em relação à média estatística para a região;

Desta forma, sobre o conceito de seca, as diferentes definições ancoram suas abordagens em enlaces estatísticos, quando, por vezes, esquecem as implicações sociais e, quando se referem às mesmas, o fazem em favor de apelos econômicos, desconsiderando as ações antrópicas que potencializam os efeitos das secas. Portanto, sem pretender uma definição universalizada de seca, baseada no histórico das secas estudadas, propomos a seguinte definição: Seca é quando a disponibilidade hídrica de uma região, impactada pela dinâmica hidrológica, é insatisfatória para o abastecimento da demanda em condições regulares, trazendo consequências para as relações humanas e ecológicas.

Com esta definição, ao se fazer referência à disponibilidade hídrica, aborda-se as classificações de seca meteorológica e agrícola, diretamente associadas à ocorrência de precipitação. Relacionandoa com a demanda, a definição de seca conecta-se aos interesses de consumo da população, da indústria, da agricultura e do comércio, contemplado, portanto, a definição de seca hidrológica. Diz-se de demanda em condições regulares para eliminar do conceito de seca o desabastecimento repentino e por curtos intervalos de tempo, causado, por exemplo, pelo aumento abrupto do consumo de água por populações flutuantes em períodos festivos em pequenas cidades. Sobre as consequências da seca nas relações humanas, inclui-se: as relações entre os membros sociais, com a possibilidade de levar a conflitos pelo acesso à água; as relações de trabalho, causando subemprego ou escassez dele; relações políticas pela exploração da fragilidade das pessoas atingidas pela seca em favor de interesses políticos e; migrações. Por fim, diz-se ambiental com a possibilidade de desertificação, incêndios e perda da biodiversidade.

\section{OCUPAÇÃO DO TERRITÓRIO CEARENSE E DENSIDADE POPULACIONAL PREPARAM O CENÁRIO PARA A SECA ATUAR}

A avaliação de uma seca passa, inevitavelmente, pelo entendimento de seu histórico e dos impactos a ela associados (Mishra \& Singh, 2010), de maneira que os registros das secas são relevantes para a definição das atividades humanas, de interesse para a sociedade. Portanto, a ocorrência de secas e a ocupação humana mostram uma sensível relação, ou seja, a seca é proporcionalmente catastrófica em territórios com intensa ocupação e demanda hídrica.

No Ceará, o adensamento populacional, somado ao escasso planejado das intervenções hidráulicas, deu à seca oportunidade de tornar-se significativa em diversas ocasiões desde o início da ocupação do território. Foi neste cenário em que se constituiu uma sociedade das chuvas, diante da incerteza sobre a ocorrência de precipitações significativas. Vale salientar que cerca de $92 \%$ do território do estado do Ceará está submetido à influência da semiaridez (Albuquerque et al., 2014). Com o passar do tempo, a necessidade de intervenção e de planejamento tornou-se evidente.

Nesta abordagem histórica da ocupação do território cearense e da formação de uma sociedade vulnerável à escassez hídrica, é necessário fazer referência às grandes secas, as quais deram origem 
às medidas governamentais que buscaram mitigar os seus efeitos negativos. Para compreender este contexto, partimos da atividade pecuária colonial.

A criação de gado foi para o Ceará o vetor de ocupação do território pelo colonizador. Em sua obra "Capítulos de História Colonial" (Abreu, 1998), Capistrano de Abreu referia-se ao Ceará como "Civilização do Couro", em alusão a todos os objetos do cotidiano fabricados a partir do couro e que correspondiam a um modo de vida que integrava sociedade e força produtiva. Sem grandes investimentos e utilizando técnica simples, a criação extensiva de gado tinha baixa rentabilidade comparada à economia do açúcar (Jucá Neto, 2014). Enquanto a atividade açucareira era predominante litorânea, a pecuária colonial se orientava pelas vias hidrográficas para acessar os sertões.

Foi a criação de gado responsável por mover as fronteiras nordestinas para além do litoral, interiorizando a ocupação do território. Vale lembrar a determinação da Coroa Portuguesa em 1701 de afastar a criação em dez léguas da área do plantio da cana. Portanto, a criação de gado teve uma condição subsidiária, de crescimento vegetativo, sendo responsável e herdeira de um processo migratório do litoral canavieiro para o sertão criador (Furtado, 1987). Salienta-se que, em termos históricos, a compreensão da ocupação dividia o território em litoral e sertão, não havendo uma compreensão geográfica mais elaborada, tal como atualmente.

No entanto, ao analisar-se o planejamento da economia colonial da perspectiva do mercado interno, a criação de gado ganha status mais amplo que de atividade acessório, como quando avaliada em relação ao mercado externo. Para o desenvolvimento do mercado interno merece destaque a técnica de salga da carne, que incrementou o fluxo comercial (Girão, 1984, 2000). Devido aos desgastes da travessia entre as fazendas de criação e os mercados consumidores, os animais apresentavam baixo valor de venda. Nisto, a técnica de salgar a carne agregou novo valor de mercado comparado à venda do boi em pé, e adicionalmente evitava-se o imposto conhecido como 'subsídio do sangue' (Braga, 1947), cobrado sobre o boi abatido.

Nesse contexto, o vale do Jaguaribe presenciou a intensificação das atividades comerciais entre as cidades de Icó (Bacia do Salgado) e Aracati (Bacia do Baixo Jaguaribe). E mais, as oficinas de carne, onde ocorriam os processos de secagem e salga da carne, extração de gordura e onde os ossos eram amontoados e queimados, instalaram-se em Acaraú, Itapajé, Russas, Quixeramobim, Coreaú, Cariris Novos e Inhamuns (Jucá Neto, 2014). Assim, as freguesias cearenses se multiplicavam e rendiam dízimos por suas atividades à Coroa Portuguesa.

Outros registros históricos que corroboram a pecuária como motor da expansão territorial cearense foram os pedidos de concessão de sesmarias, que eram terras doadas como parte da política de povoamento da Coroa Portuguesa, das quais 91\% tinham como justificativa a necessidade de terra para criar gado (Jucá Neto, 2014, p. 195). Todavia, não se pode esquecer que a expansão da pecuária não se fez em terras desabitadas, por exemplo, os índios Tapuyas e Payacus foram empecilho à rápida ocupação do Jaguaribe (de Menezes, 1901, p. 217). O conflito entre colonizadores e indígenas foi intenso, os colonizadores eram vistos como outra tribo, passiva de conflito, passiva de alianças. Desta forma, em pleno processo de extermínio dos indígenas, os índios Icós e Calabaças apoiaram a família Monte, enquanto que os índios Tapuias apoiaram a família Feitosa, pela disputa de terras (Jucá Neto, 2014, p. 219). Um novo jogo de poder se apresentou, onde os nativos foram usurpados e tiveram suas rivalidades exploradas como estratégia militar. Esta é uma parte da História do Ceará em que a violência foi o argumento mais entoado diante do conflito pela ocupação da terra. Contudo, as fazendas de gado se firmaram, prevaleceu o capitalismo comercial em detrimento ao modo de vida coletivo dos indígenas. Em torno das fazendas de criação de gado surgiram os primeiros núcleos urbanos, as vilas, marcadas pela miscigenação.

Um golpe contra a economia pecuária veio com uma grande seca ocorrida entre 1790 e 1793, e não retornou ao impulso anterior, dando lugar à ascensão do cultivo do algodão, direcionado ao mercado externo. Nesse contexto, a cidade de Fortaleza emergiu como centro comercial e urbano, para onde se dirigiu a imensa massa populacional, que ocupara o sertão levada pela criação do gado e, nesse período, retornava para o litoral em busca de socorro para as desgraças decorrentes das secas. Registrem-se as dificuldades encontradas no trajeto em direção ao litoral, devido à fome, doenças e crimes. As estradas, muitas vezes, transformaram-se em cemitérios (Neves, 2007, p. 79).

Apresenta-se incontestável que a seca de 1877 a 1879 foi a maior catástrofe ocorrida no Nordeste brasileiro, já que a região perdeu mais de meio milhão de vidas, desarticulando o povoamento dos sertões (Guerra, 1981, p. 32). 0 farmacêutico Rodolfo Teófilo calculou que em dezembro de 1878 foram contabilizadas 80.000 pessoas com varíola. No dia 10 de dezembro do mesmo ano foram enterrados 1.004 cadáveres, e 230 ficaram para o dia seguinte porque as 40 pessoas contratadas como 
coveiros não conseguiram sepultá-las no mesmo dia. Este dia ficou conhecido como dia dos mil mortos (Ponte, 2001; Neves, 2007, p. 83). À época Fortaleza contava com uma população aproximada de 30 mil pessoas, mas em três anos de seca chegaram à capital cerca de 100 mil retirantes (Ponte, 2001, p. 84). Como apresentado nos registros históricos, a cidade de Fortaleza, incluindo seus governantes e sua população, não estavam preparados para lidar com essa massa humana flagelada pela seca. A partir da seca de 1877, a escassez da chuva se tornou um problema estatal (Campos, 2014, p. 75).

Como em outras cidades do País, durante a virada do século XIX para o século XX a cidade de Fortaleza passou por um processo de remodelação pautado na nova ordem urbana, baseada no cientificismo e racionalidade dominantes na Europa (Ponte, 2001, p. 25). Um dos efeitos sociais da reformulação urbana esteve claro durante a seca de 1915: diante do discurso predominante na nova e moderna cidade de Fortaleza, os retirantes eram considerados um incômodo que ameaçava a segurança e a moralidade pública, tendo sido alvo de técnicas de controle social que objetivavam impedir a chegada de retirantes à cidade. Assim, para que Fortaleza não sofresse com mais a invasão de seu território como a ocorrida em 1877 a 1879, na seca de 1915 foi criado o Campo de Concentração (de flagelados da seca) do Alagadiço, que se tornou um campo de morte. Rodolfo Teófilo, que não concordava com a construção do campo devido às condições sanitárias que favoreciam a proliferação de doenças, afirmou que o campo havia se transformado em um cemitério de crianças (Teófilo, 1922; Neves, 2007, p. 88).

\section{POLÍTICA SOBRE AS SECAS}

Sendo a seca reconhecida como problema de Estado, e com o conhecimento acumulado sobre esse fenômeno, a solução hidráulica foi apresentada (Campos, 2014, p. 75), constituída pela ideia de acumulação em reservatórios de água escoada durante os períodos chuvosos, para utilização nos períodos secos. Nesse momento, a seca era um evento desastroso a ser combatido e a ideia era criar as condições de fixar o homem no campo. Assim, se formava um escudo em torno da capital litorânea, que ficaria livre da invasão dos flagelados da seca (Neves, 2007, p. 88).

Quando da ocorrência da seca de 1932, por exemplo, os governos federal e estadual se articularam e foi criada uma Secretaria de Secas no Ceará. Dentre as ações para fixar o homem no campo estavam: construção de poços, barragens e açudes, que faziam parte da solução hidráulica. Além disso, ao invés de um único campo de concentração, em 1932 foram criados sete campos, dos quais cinco em localidades do interior (Crato, Cariús, Quixeramobim, Ipu e Senador Pompeu) e dois em Fortaleza (Neves, 2007, p. 91). Esses campos estavam associados a construções hidráulicas, frentes emergenciais, e apresentaram uma nova realidade de trabalho, as obras, para os agricultores e criadores de antes, agora operários. As verbas crescentes destinadas às obras de combate à seca, os organismos de atendimento aos flagelados, a teatralização nas distribuições de alimentos, tudo contribuía para a formalização da indústria da seca (Neves, 2007, p. 92). Neste aspecto, a seca catastrófica se apresentava como instrumento político, de uma política distorcida de princípios que tomava proveito da fragilidade social, potencializada pela seca, para interesses eleitoreiros.

Na seca de 1942, em plena Segunda Guerra Mundial, destacou-se a extração da borracha nos seringais da Amazônia. O Ciclo da Borracha pode ser dividido em duas fases: a primeira que vai de 1870 a 1912, e a segunda fase, iniciada durante a Segunda Guerra Mundial quando o Japão atacou os Estados Unidos, que perderam o acesso ao cultivo de borracha no Sudoeste asiático bloqueado, dando início a um novo ciclo de exploração. Além de alternativa de trabalho para os flagelados da seca na região Nordeste, a extração do látex promoveu a ocupação da Amazônia. No entanto, nesta segunda fase, o que os cearenses encontraram nos seringais da Amazônia foi trabalho análogo ao escravo (Secreto, 2007, p. 131). Nesse período, resultado de um acordo entre Brasil e EUA, criou-se um novo campo, onde funcionários norte-americanos inspecionavam a seleção de novos trabalhadores para os seringais (Neves, 2007, p. 93).

Mesmo com o fim da Guerra e do Estado Novo no Brasil, o período democrático que se seguiu teve nas obras públicas de combate à seca uma fonte sólida de poder e influência, onde ocorria trabalho, distribuição de alimentos e assistência médica. Desta forma, durante a seca de 1952 e 1953, mesmo pela via do voto direto, as relações de trabalho e dependência entre governo e flagelados permaneceram, dando continuidade ao jogo político eleitoreiro. Nesse momento, os saques aos mercados foram os formulários para reivindicar assistência, que eram respondidos com novos projetos, mais obras como açudes e estradas. Assim, as migrações dos flagelados das secas ganharam uma nova rota além da capital litorânea, a rota das obras (Neves, 2007, p. 95). 
Na seca de 1958-1959, foi mais evidente a institucionalização política das secas. Desta forma, os órgãos criados em função das secas, diga-se o Departamento Nacional de Obras Contra as Secas (DNOCS, criado em 1909), Banco do Nordeste (BNB, criado em 1952) e posteriormente a (Superintendência do Desenvolvimento do Nordeste (SUDENE, criada em 1959), passaram a ter seu controle disputado por grupos de influência política com objetivos eleitorais. Assim, a SUDENE havia se tornado o administrador intermediário para se acessar politicamente uma sociedade fragilizada pelas secas. Situação que perdurou por décadas quando em 1983, as imagens das consequências da seca alcançaram a mídia televisiva e as autoridades foram consideradas culpadas pela omissão, cujas consequências foram milhões de mortes no Nordeste, causadas pela fome e pelas doenças (Neves, 2007, p. 100). Apesar de qualquer intervenção político eleitoreira que essas instituições tenham sofrido, é inegável que tenham contribuído significativamente para o conhecimento sobre secas na região semiárida do Brasil, bem como para a efetivação da política de açudagem como estratégia de adaptação da sociedade.

Desde meados do século XX, as políticas referentes aos recursos hídricos passaram por mudanças (Medeiros \& Sivapalan, 2020) e têm estado na pauta mundial, sendo o tema ambiental associado aos debates de desenvolvimento econômico. O estado do Ceará conta com a Fundação Cearense de Meteorologia e Recursos Hídricos (FUNCEME), criada em 1974, e está na base da produção de dados, conhecimento e monitoramento. Ainda no contexto das organizações estaduais, em 1993 foi criada a Companhia de Gestão dos Recursos Hídricos (COGERH), que desenvolve ações de monitoramento para o uso racional da água.

A política sobre a seca, diante da conferência global sobre o clima (Rio 92) quando foi redigida a Agenda 21, teve atenção com a temática da semiaridez. Nesse novo contexto, a erradicação da pobreza foi descrita como um objetivo. Então, o Brasil desenvolveu vários programas para atender este objetivo, como Bolsa Família, Água para Todos e Seguro Safra. Entre as medidas estruturais, destacase a transposição do rio São Francisco (Campos, 2014, p. 82), que pode trazer um novo paradigma para a compreensão da seca e ultrapassa a centralização dada à açudagem como solução hidráulica, apontando para a transposição de bacias hidrográficas como nova solução para convívio com as secas.

Transposição entre bacias hidrográficas é a transferência de água de uma bacia para ser usada em outra, técnica utilizada desde a Antiguidade, como por exemplo, o transporte de água por centenas de quilômetros nos aquedutos romanos. No Ceará, destaca-se a transposição de águas da Bacia do Jaguaribe para a Região Hidrográfica Metropolitana de Fortaleza, cujo sistema de abastecimento é formado por uma rede de cinco açudes: Pacajus, Pacoti, Riachão, Gavião e Acarape do Meio, interligados entre si por canais e adutoras. Desta forma, o açude Castanhão, maior obra da solução hidráulica no Ceará, com capacidade para acumular 6,1 bilhões de $\mathrm{m}^{3}$, pereniza o rio Jaguaribe (Azevedo et al., 2005, p. 35) e abastece a Região Metropolitana de Fortaleza e o Complexo Industrial e Portuário do Pecém, principais centros de demanda hídrica. Ou seja, a transposição entre bacias hidrográficas no Ceará encontra apoio na estrutura hidráulica da açudagem.

Apesar de todos os esforços relacionados à solução hidráulica, é persistente a mobilização dos carros pipas na paisagem sertaneja. Nesse contexto, a Operação Carro-Pipa é resultado de cooperação técnica e financeira entre os Ministérios da Integração Nacional e da Defesa, realizando a contratação e pagamento dos proprietários de caminhão do tipo carro-pipa (conhecidos regionalmente como pipeiros), para entrega de água, sob coordenação do Exército Brasileiro e supervisão do Ministério da Integração Nacional (Brasil Neto, 2019, p. 410). No entanto, nas comunidades rurais mais vulneráveis e remotas, a Operação Carro-Pipa tem sido instrumento de campanhas políticas, bem como instrumento comercial para venda de caminhões e água bruta por preços elevados (Gutiérrez et al., 2014, p. 100).

\section{AVALIANDO AS SECAS E SEUS IMPACTOS SOBRE A SOCIEDADE}

A avaliação da magnitude e dos efeitos de uma seca pressupõe a utilização de índices de severidade de seca (Mishra \& Singh, 2010, p. 207), e a maioria dos índices disponíveis na literatura utilizam a precipitação pluviométrica, isoladamente ou em combinação com outros fatores.

Neste estudo, realizou-se a classificação de secas utilizando o Índice de Porcentagem Normal (IPN), que é calculado simplesmente pela razão entre a precipitação acumulada no respectivo ano e a precipitação anual média de longo período, caracterizada como normal climatológica. Ou seja, o IPN indica a ocorrência de seca meteorológica. A precipitação média de longo período foi obtida pela média aritmética dos registros de 107 anos, de 1912 a 2018. A Tabela 1 apresenta a classificação proposta a partir do IPN, utilizada para a caracterização das secas meteorológicas neste estudo. 
Tabela 1. Classificação do Índice de Porcentagem Normal (IPN) para caracterização de secas meteorológicas

\begin{tabular}{c|c}
\hline Intervalo & Classificação \\
\hline IPN $\geq 1,5$ & Precipitação excepcional \\
\hline $1,3 \leq$ IPN $<1,5$ & Precipitação plena \\
\hline $1,1 \leq$ IPN $<1,3$ & Precipitação moderada \\
\hline $0,9 \leq$ IPN $<1,1$ & Precipitação normal \\
\hline $0,7 \leq$ IPN $<0,9$ & Seca moderada \\
\hline $0,5 \leq$ IPN $<0,7$ & Seca severa \\
\hline IPN $<0,5$ & Seca extrema \\
\hline
\end{tabular}

Para a caracterização pluviométrica, foram analisadas 633 estações disponíveis no Sistema de Informações Hidrológicas da Agência Nacional de Águas (2018). No Ceará, os primeiros registros pluviométricos oficiais datam de 1910, e em 1912 passou a existir um número significativo de estações pluviométricas, que seguem registrando as chuvas até o presente ou foram substituídas por outras estações nas proximidades. Nesta análise histórica de secas, para a qual a extensão temporal da série pluviométrica é fundamental, foram selecionadas apenas as estações com séries centenárias (de 1912 a 2018), resultando em 41 estações espalhadas pelo território cearense (Figura 1).

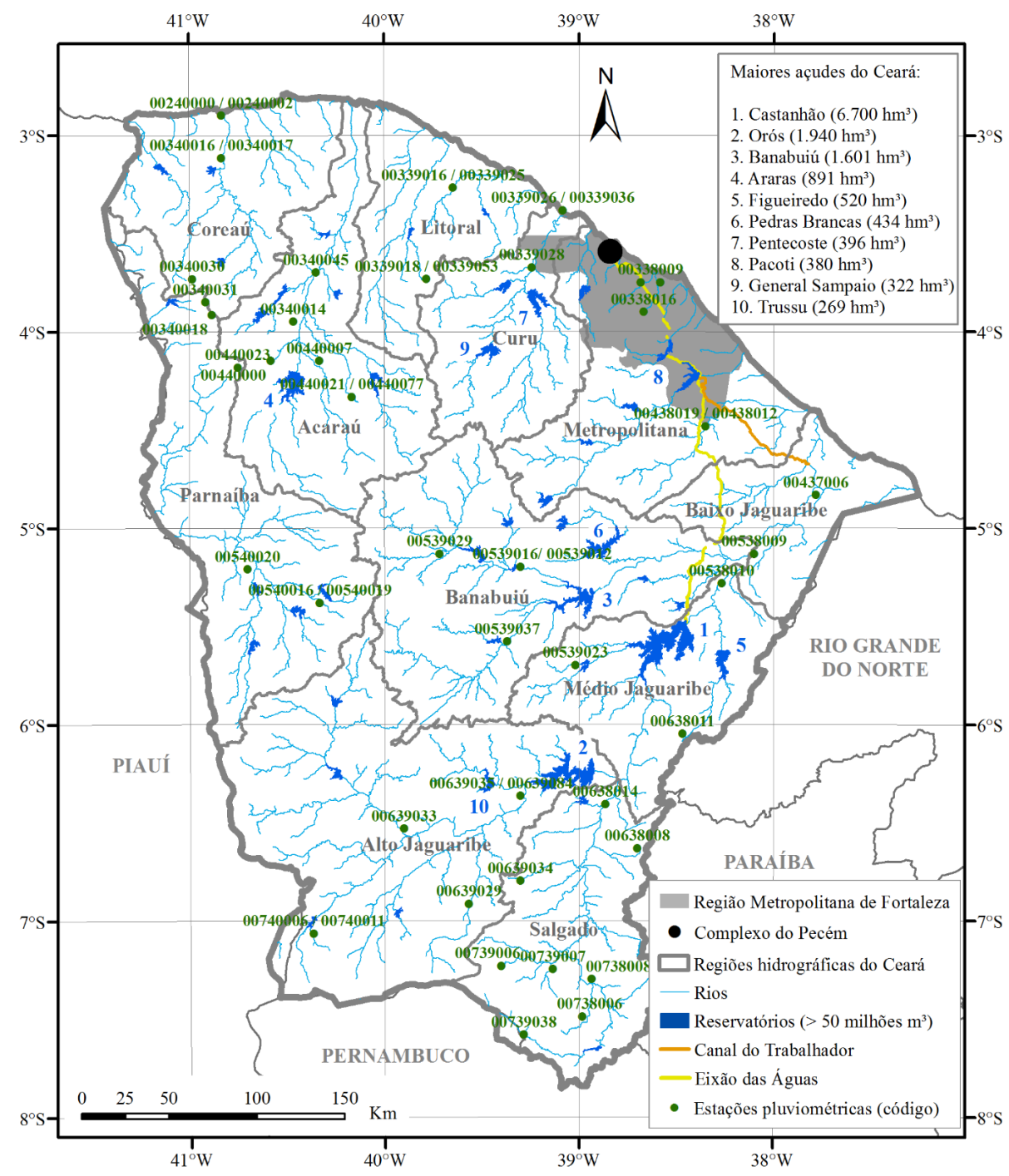

Figura 1. Aspectos hidrográficos do Estado do Ceará e as estações pluviométricas utilizadas no estudo 
Como a seca não é um fenômeno climatológico abrupto e seus efeitos são percebidos ao longo do tempo, procedeu-se a caracterização integral das séries pluviométricas, e não apenas dos períodos secos. Neste estudo, a ocorrência de secas meteorológicas foi confrontada com a aquisição de capital hidráulico, definido por González et al. (2017, p. 200) como “[...] bens duradouros utilizados na produção, armazenamento, reciclagem, interconexão ou transporte de água". Para avaliar o efeito do capital hidráulico sobre as consequências das secas, convém considerar também a classificação de anos chuvosos (chuva moderada, chuva plena e chuva excepcional). Isso porque o capital hidráulico é capacitado para atuar tanto durante as chuvas e também nos períodos de seca. Considerando-se que o homem tem com a natureza uma relação de uso e intervenção, resultando uma natureza humanizada (Santos, 1999, p. 83), tratar da açudagem sem abordar as chuvas é ter meia natureza humanizada. Assim, embora a materialidade do capital hidráulico se faz a partir das secas, a natureza dialética do semiárido (entre seca e chuva) estaria incompleta e inconsistente sem o conhecimento das chuvas.

Os dados pluviométricos foram agrupados para todo o estado do Ceará, os registros diários tendo sido totalizados anualmente, calculando-se o Índice de Porcentagem Normal para cada ano da série (Figura 2).

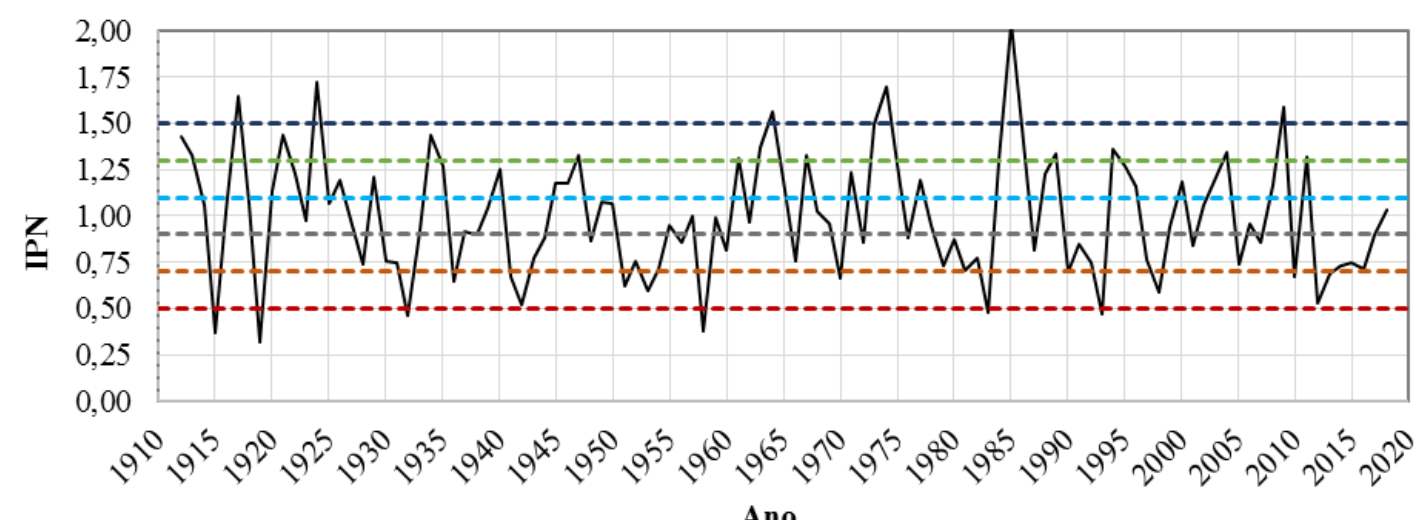

Figura 2. Índice de Porcentagem Normal para o Ceará e ocorrência de secas meteorológicas. As linhas tracejadas referem-se à classificação de secas apresentada na Tabela 1.

Na Figura 2, é possível identificar anos de secas meteorológicas extremas que marcaram a história do Ceará, como em 1915, 1919 e 1958, assim como sequências de anos com baixas precipitações, como em 1930-1933, 1979-1983, 1990-1993 e o período mais longo com precipitações abaixo da média, de 2012-2017.

A Tabela 2 apresenta o percentual de ocorrência de secas meteorológicas no período de estudo, de acordo com sua intensidade e duração. É possível verificar o elevado percentual de anos com precipitação abaixo da média ( $43 \%$ de anos com seca moderada ou mais intensa), embora a ocorrência de seca estrema esteja limitada a $6 \%$ dos anos. A ocorrência de 4 anos consecutivos de seca é de 5\%, e uma única vez foi registrada uma sequência de 6 anos com baixas precipitações, no período de 2012 a 2017. A Figura 3 apresenta o acumulado do déficit percentual em relação à precipitação média, para sequências de anos secos.

Tabela 2. Ocorrência de anos consecutivos de seca meteorológica no Ceará com base no Índice de Porcentagem Normal

\begin{tabular}{c|c|c|c}
\hline \multirow{2}{*}{$\begin{array}{c}\text { Anos } \\
\text { consecutivos }\end{array}$} & \multicolumn{3}{c}{ Intensidade de seca igual ou mais intensa } \\
\cline { 2 - 4 } & Moderada & $16 \%$ & Severa \\
\hline 1 ano & $43 \%$ & $2 \%$ & $6 \%$ \\
\hline 2 anos & $12 \%$ & $0 \%$ & $0 \%$ \\
\hline 3 anos & $7 \%$ & $0 \%$ & $0 \%$ \\
\hline 4 anos & $5 \%$ & $0 \%$ \\
\hline
\end{tabular}




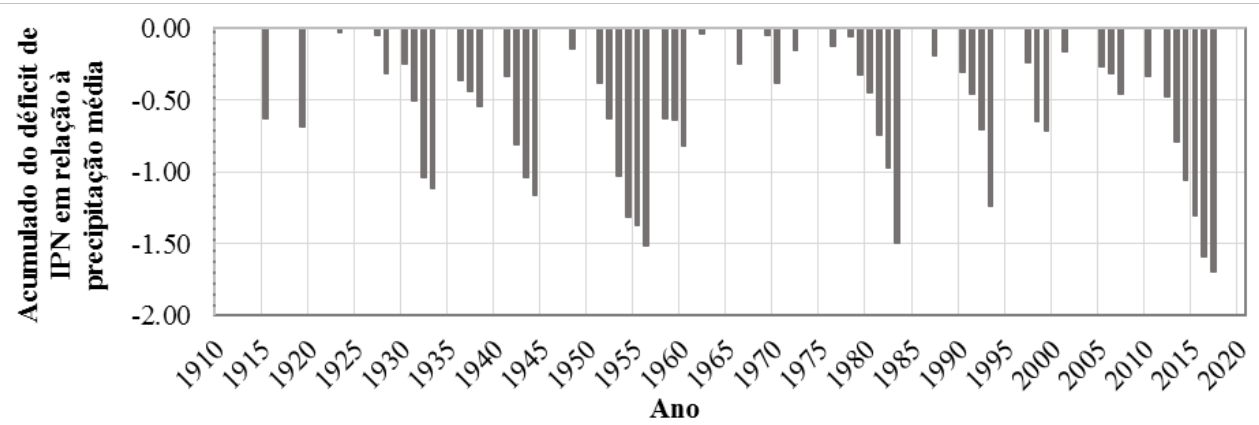

Figura 3. Acumulado do déficit percentual em relação à precipitação média, para sequências de anos secos

Dados censitários da população cearense (Instituto Brasileiro de Geografia e Estatística, 2006; Instituto Brasileiro de Geografia e Estatística, 2011) no período de estudo (início do século XX ao ano 2015 - ver Figura 4) foram utilizados como indicador da evolução da demanda hídrica. Ainda que se admita proporcionalidade direta entre população e demanda por água, é sabido que a demanda depende de setores econômicos predominantes, padrões de consumo da sociedade, medidas de controle de uso da água e outros fatores que variam ao longo do tempo. No entanto, extrapola o escopo deste estudo a quantificação detalhada da demanda hídrica em toda a extensão temporal considerada, de maneira que a população é utilizada apenas como referência para caracterização dos efeitos das secas. Observa-se que, apesar da ocorrência frequente de secas (Figura 2 e Tabela 2), a população cearense apresentou crescimento médio de 1,8\% ao ano a partir de 1960, com pico de 3,0\% ao ano na década de 1960 (Figura 4).

Catalogou-se também a evolução de açudes estratégicos, aqueles construídos pelo poder público e utilizados para abastecimento de importantes centros de demanda hídrica, e da capacidade de acumulação de água (Figura 3) como indicador da disponibilidade hídrica.

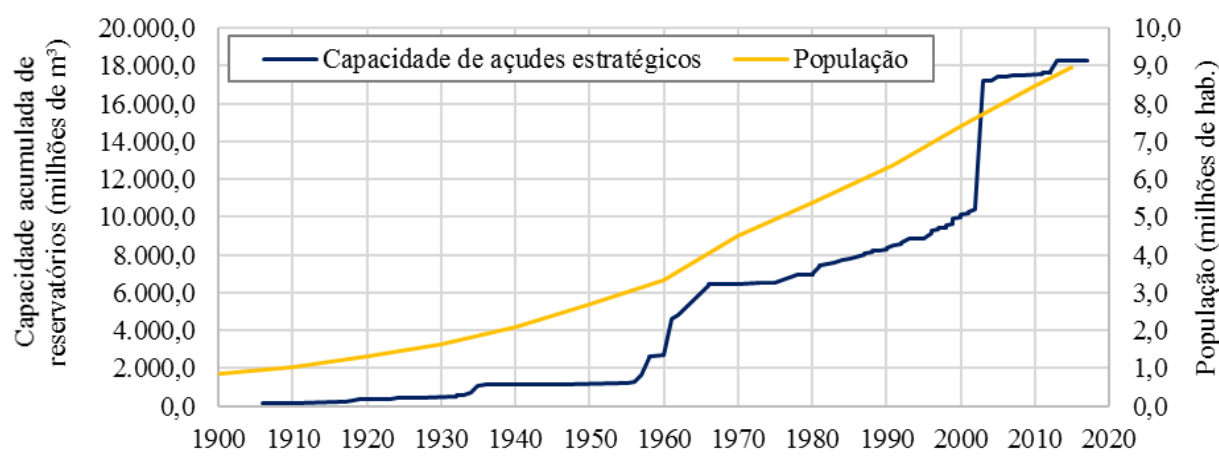

Figura 4. População e capacidade de acumulação de água em açudes estratégicos no Ceará no período de 1900 a 2018 (Fontes dos dados: Instituto Brasileiro de Geografia e Estatística, 2006; Instituto Brasileiro de Geografia e Estatística, 2011 e SRH (Ceará, 2019), respectivamente)

Ressalta-se que a atenção dada neste estudo aos açudes estratégicos se deve à priorização dessa solução na política de recursos hídricos do Ceará durante o século XX (Medeiros \& Sivapalan, 2020). Estima-se que aproximadamente $90 \%$ do suprimento de água no estado seja proveniente de açudes, mas é importante destacar a complementariedade entre essas estruturas e fontes alternativas de abastecimento, como poços e cisternas, para a convivência com as secas (de Araújo \& Bronstert, 2016).

Silva et al. (2007) realizaram levantamento detalhado de informações hidrogeológicas no estado do Ceará e concluíram que a Região Metropolitana de Fortaleza é uma das áreas com maior potencial de exploração de águas subterrâneas, sendo também onde está concentrada grande parte da demanda hídrica. Os autores argumentam ainda que “[...] cerca de $41 \%$ dos sistemas públicos de abastecimento de água empregam poços como mananciais, atendendo aproximadamente 1,1 milhão de pessoas (Silva et al., 2007) [...]" (pouco mais de $10 \%$ da população) e que "[...] no cristalino, o grau de conformidade com padrões de potabilidade atinge 47\%, enquanto em bacia sedimentar chega a 90\%"(Silva et al., 2007). A importância das águas subterrâneas para abastecimento ganha destaque nos períodos de seca, como pode ser ilustrado pelo levantamento de perfuração de poços realizado pela 
Superintendência de Obras Hidráulicas - SOHIDRA: a taxa de perfuração de poços pela instituição era de aproximadamente 200 estruturas por ano entre 1987 e 2012, tendo aumentado $40 \%$ ao ano entre 2012 e 2018 e atingindo quase 2.000 poços implantados em 2018. Esse aumento da taxa de implantação de poços coincide com o período da última grande seca, que perdurou de 2012 a 2017, sendo o ano de 2018 ainda seco em algumas regiões do estado.

A Tabela 3 apresenta a ocorrência de secas meteorológicas a partir do método IPN e de registros históricos versus a capacidade de acumulação de água em reservatórios estratégicos no Ceará. A elevada coincidência de indicação de seca pelo IPN e pelos registros históricos sobre o fenômeno (Guerra, 1981; Neves, 2007; Sarmento, 2005; Rêgo, 2008), indica que anos com baixas precipitações (seca meteorológica) produziram impactos sobre a sociedade (seca hidrológica) em grande parte do período de estudo, particularmente até o início da década de 1950. Observa-se também, a partir da mesma tabela, que nesse período a capacidade de acumulação de água no estado era ainda incipiente, equivalente a menos de $10 \%$ da atual capacidade. No entanto, desde a década de 1930 os governos federal e estadual se articulavam para fixar o homem no campo através da construção de obras hidráulicas, especificamente poços e barragens.

Durante a década de 1940 até meados de 1950, a aquisição do capital hidráulico, particularmente de açudes estratégicos, não foi significativa. No entanto, na década de 1960 ampliou-se de maneira expressiva a capacidade de armazenamento hídrico no Ceará, com a construção dos reservatórios Orós em 1961, e Banabuiú em 1966, com capacidades de 1.940 x $10^{6} \mathrm{~m}^{3}$ e 1.601 x $10^{6} \mathrm{~m}^{3}$, respectivamente (Figura 3). Desde então, vários anos com precipitações abaixo da média não produziram um quadro de escassez hídrica, não tendo sido registrados por historiadores como anos de seca (hidrológica). Ou seja, a aquisição de capital hidráulico proporcionou uma atenuação das consequências socioeconômicas das secas, diminuindo a propagação dos efeitos da baixa pluviometria sobre a sociedade.

A efetividade do acúmulo de água nos açudes estratégicos para utilização durante períodos de baixa pluviometria impulsionaram a construção de açudes nas décadas seguintes. Ademais, o aumento das taxas de crescimento populacional a partir de 1960, e a ocorrência de secas meteorológicas, foram o mote para a grande obra da hidráulica cearense, o açude Castanhão, que teve papel fundamental na manutenção do abastecimento da Região Metropolitana de Fortaleza nos anos secos de 2012 a 2017.

Tabela 3. Ocorrência de seca a partir do método IPN e de registros históricos versus capacidade de acumulação de água no Ceará

\begin{tabular}{|c|c|c|c|c|c|c|c|}
\hline \multicolumn{3}{|c|}{ Ocorrência de seca no Ceará } & \multirow[b]{2}{*}{$\begin{array}{c}\text { Capacidade } \\
\text { acumulada } \\
\left(10^{6} \mathrm{~m}^{3}\right)\end{array}$} & \multicolumn{3}{|c|}{ Ocorrência de seca no Ceará } & \multirow[b]{2}{*}{$\begin{array}{c}\text { Capacidade } \\
\text { acumulada } \\
\left(10^{6} \mathrm{~m}^{3}\right)\end{array}$} \\
\hline Ano & $\begin{array}{c}\text { Este } \\
\text { estudo } \\
\text { (IPN) }\end{array}$ & $\begin{array}{c}\text { Registro } \\
\text { na } \\
\text { literatura }\end{array}$ & & Ano & $\begin{array}{c}\text { Este } \\
\text { estudo } \\
\text { (IPN) }\end{array}$ & $\begin{array}{c}\text { Registro } \\
\text { na } \\
\text { literatura }\end{array}$ & \\
\hline 1915 & Extrema & Sim & 186,5 & 1979 & Moderada & Sim & $7.057,6$ \\
\hline 1919 & Extrema & Sim & 344,9 & 1980 & Moderada & Não & $7.116,1$ \\
\hline 1928 & Moderada & Não & 532,4 & 1981 & Moderada & Não & $7.548,3$ \\
\hline 1930 & Moderada & Sim & 532,4 & 1982 & Moderada & Não & $7.577,0$ \\
\hline 1931 & Moderada & Não & 532,4 & 1983 & Extrema & Sim & $7.727,4$ \\
\hline 1932 & Extrema & Sim & 610,3 & 1987 & Moderada & Não & $8.265,9$ \\
\hline 1933 & Moderada & Não & 637,1 & 1991 & Moderada & Não & $8.673,0$ \\
\hline 1936 & Severa & Sim & $1.206,7$ & 1992 & Moderada & Não & $8.858,1$ \\
\hline 1938 & Moderada & Não & $1.206,7$ & 1993 & Extrema & Sim & $9.100,4$ \\
\hline 1942 & Severa & Sim & $1.206,7$ & 1997 & Moderada & Não & $9.679,9$ \\
\hline 1951 & --- & Sim & $1.213,1$ & 1998 & Severa & Sim & $9.838,2$ \\
\hline 1952 & Moderada & Não & $1.214,0$ & 2001 & Moderada & Não & $10.657,5$ \\
\hline 1954 & Moderada & Não & $1.265,9$ & 2005 & Moderada & Não & $17.828,9$ \\
\hline 1956 & Moderada & Não & $1.339,2$ & 2007 & Moderada & Não & $17.952,6$ \\
\hline 1958 & Extrema & Sim & $2.692,7$ & 2010 & Severa & $*$ & $17.960,8$ \\
\hline 1960 & Moderada & Sim & $2.748,5$ & 2012 & Severa & $*$ & $18.569,3$ \\
\hline 1966 & Moderada & Não & $6.538,6$ & 2013 & Severa & * & $19.098,4$ \\
\hline 1968 & --- & Sim & $6.538,6$ & 2014 & Moderada & $*$ & $19.098,4$ \\
\hline 1970 & Severa & Sim & $6.581,1$ & 2015 & Moderada & $*$ & $19.106,4$ \\
\hline 1972 & Moderada & Sim & $6.581,1$ & 2016 & Moderada & $*$ & $19.106,4$ \\
\hline 1976 & Moderada & Não & $6.620,5$ & 2017 & Moderada & $*$ & $19.108,4$ \\
\hline
\end{tabular}

Fontes dos registros históricos sobre secas: Guerra (1981), Neves (2007), Sarmento (2005), Rêgo (2008). *0s registros históricos sobre secas consultados neste estudo se estendem somente até o ano de 2008 , mas há bibliografia científica sobre a seca de 2012 a 2017. 
A partir da Figura 2 e da Tabela 3, é possível fazer algumas observações específicas sobre a ocorrência de secas e a aquisição do capital hidráulico:

- $\quad$ Os anos de seca mais intensa ocorridos na década de 1910 foram os de 1915 e 1919. Mesmo sendo possível considerar como anos de seca isolados, estes anos secos foram catastróficos para a sociedade cearense, quando o capital hidráulico era irrisório: em 1910 e 1920, a capacidade de acumulação era de 0,2 e 0,3 $\mathrm{hm}^{3} / 1000$ hab., respectivamente;

- Sequências de anos de seca, como nas décadas de 1960 e 1970, de intensidade moderada e severa, foram graves ameaças ao abastecimento, mesmo quando instalado capital hidráulico. Nessas décadas, houve uma seca hidrológica, relacionada ao aumento da população e consequentemente da demanda hídrica. Mesmo com os açudes Orós (1961) e Banabuiú (1966) recém construídos, o que elevou a capacidade de acumulação a 1,4 hm³/1000 hab no fim da década de 1960, aportes hídricos significativos só ocorreram em 1964 (Orós) e 1974 (Orós e Banabuiú). Portanto, esses reservatórios foram efetivos para o abastecimento hídrico somente a partir de anos com elevada pluviometria, ou seja, algum tempo após sua implantação;

- Não há registro de seca que combinasse extensão de tempo e intensidade como ocorrido entre os anos de 2012 e 2017. Nesse contexto, o açude Castanhão, maior obra hidráulica cearense e que aumentou a capacidade de acumulação para mais de $2 \mathrm{hm}^{3} / 1000$ hab., resguardou a população da Região Metropolitana de Fortaleza dos impactos das secas de 2010 e entre 2012 a 2015. Em termos de precipitações, as secas de 2012 e 2016 não foram mais severas que as 1915 e 1919, mas apesar dos avanços conquistados com a aquisição de capital hidráulico, ainda impactaram as populações (Rabelo \& Lima Neto, 2018).

A comparação entre os eventos de secas de 1915 e 2015 demonstra que, apesar de mais crítico o período último, de um modo geral as consequências foram muito menos danosas que naquele, ampamente debatido nos registros históricos. Fica evidente a relevância da aquisição do capital hidráulico desde aquele primeiro evento, garantindo melhores condições de convivência com o fenômeno das secas pela sociedade cearense.

O sucesso da política da construção de açudes estratégicos pelo poder público levou proprietários rurais e comunidades remotas a construirem seus próprios açudes de menores dimensões, produzindo uma densa rede de reservatórios superficias (de Araújo \& Medeiros, 2013). Apesar da existência de mais de 20.000 açudes não estratégicos no Ceará (Pereira et al., 2019), a manutenção do abastecimento de grandes centros de demanda pelos açudes estratégicos, mesmo em períodos de seca meteorológica, não ocorre na mesma escala que a do meio rural. Exemplo disso foi a seca de 2012 a 2017, quando o fornecimento de água por meio de carros-pipa se fez necessário em grande parte do território cearense. Os valores gastos anualmente e a cobertura territorial da operação carro-pipa no Ceará são apresentados na Tabela 4.

Tabela 4. Valores gastos anualmente e cobertura da operação carro-pipa no Ceará durante a seca de 2012 a 2017

\begin{tabular}{|c|c|c|c|c|}
\hline Ano & $\begin{array}{l}\text { Valor gasto com } \\
\text { carros-pipa (R\$) }\end{array}$ & $\begin{array}{l}\text { Valor acumulado } \\
\text { (R\$) }\end{array}$ & $\begin{array}{l}\text { Municípios } \\
\text { atendidos }^{2}\end{array}$ & $\begin{array}{l}\text { Percentual } \\
\text { do total de } \\
\text { municípios }\end{array}$ \\
\hline 2012 & $27.554 .538,87$ & $27.554 .538,87$ & 171 & $93 \%$ \\
\hline 2013 & $86.346 .442,40$ & $113.900 .981,27$ & 152 & $83 \%$ \\
\hline 2014 & 124.271.101,87 & $238.172 .083,14$ & 122 & $66 \%$ \\
\hline 2015 & 176.853.359,11 & $415.025 .442,25$ & 146 & $79 \%$ \\
\hline 2016 & $249.888 .405,05$ & $664.913 .847,30$ & 133 & $72 \%$ \\
\hline 2017 & $199.063 .475,98$ & $863.977 .323,28$ & 138 & $75 \%$ \\
\hline
\end{tabular}

Fonte dos dados: Sistema Eletrônico do Serviço de Informações ao Cidadão (e-SIC), através de comunicação com o MI - Ministério da Integração Nacional. ${ }^{1}$ Valor de 2017 corresponde ao período de janeiro a setembro. ${ }^{2}$ Em 2017, municípios atendidos até o mês de setembro.

Em sua análise de secas na bacia do Jaguaribe, de Araújo \& Bronstert (2016) demonstraram através de simulações hidrológicas que os pequenos sistemas hídricos, incluindo pequenos açudes e cisternas, são incapazes de suportar secas longas sem o completo esvaziamento. Isso se deve em grande parte à própria dinâmica hidrológica da região: a) precipitações ocorrem de forma muito concentrada no espaço (Medeiros et al., 2010) e no tempo (Medeiros \& de Araújo, 2014), produzindo 
incerteza sobre o processo de enchimento dos pequenos açudes durante a quadra chuvosa; b) as elevadas taxas de evaporação observadas na região promovem intensa redução do nível da água, atingindo valores da ordem de $2,0 \mathrm{~m}$ por ano, o que pode representar uma importante parcela da acumulação nos pequenos açudes, em sua maioria rasos. A título de ilustração, a Figura 5 apresenta a dinâmica temporal de acumulação de água, no período de 2004 a 2018, em açudes de diferentes magnitudes. Na figura, é possível observar que açudes de grande porte, como Castanhão e Orós, apresentam menor variabilidade relativa do volume acumulado e maior estabilidade no processo de reservação de água. Por sua vez, açudes de pequeno porte, como o Quincoé, são mais susceptíveis a intensas flutuações no armazenamento de água e secam completamente com maior frequência.

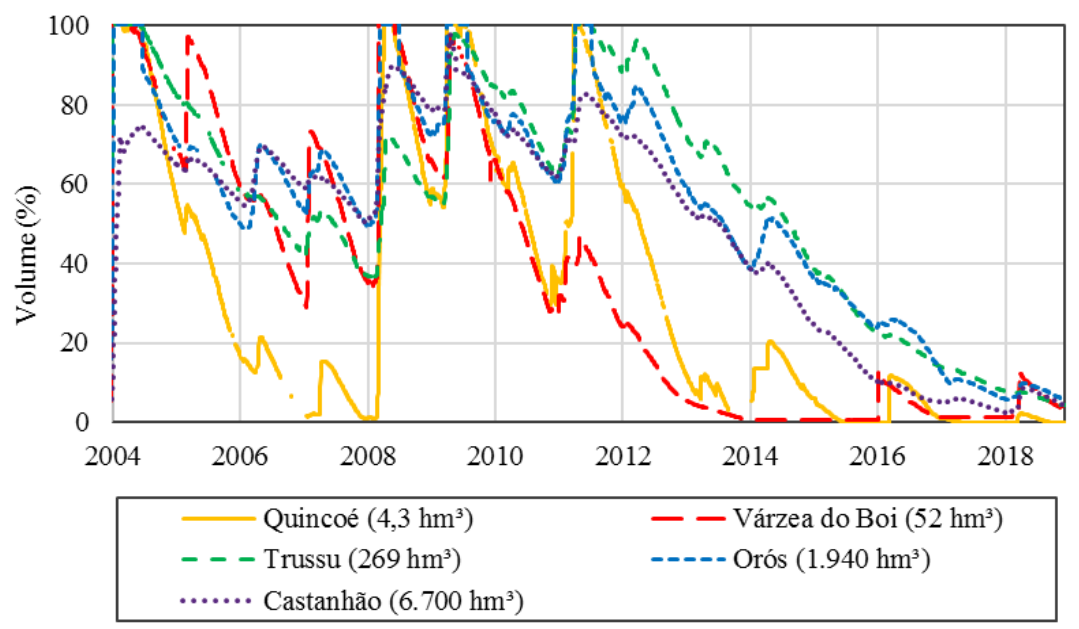

Figura 5. Dinâmica temporal da acumulação de água em açudes com diferentes capacidades, no período de 2004 a 2018 (Fonte dos dados: Companhia de Gestão dos Recursos Hídricos do Ceará, 2019)

Outro aspecto que contribui para a relativa baixa efetividade dos pequenos açudes para a convivência com as secas é a escassez de dados sobre essas estruturas (Pereira et al., 2019), que limita sua inclusão na política de recursos hídricos. De fato, Brasil \& Medeiros (2020) argumentam que os métodos desenvolvidos para a operação de grandes açudes se consolidaram como norteadores do uso da água no semiárido brasileiro, mas que sua aplicação para pequenos açudes é extremamente ineficiente.

Portanto, a aquisição de capital hidráulico, que se mostra tão relevante para garantir o abastecimento de grandes centros de demanda hídrica mesmo em períodos secos, não foi capaz de estender seus efeitos benéficos igualmente por toda a sociedade cearense. A população rural, principalmente as comunidades mais remotas, continua vulnerável à ocorrência de secas nesse sistema que acumula água de maneira concentrada em grandes reservatórios para servirem, principalmente, às zonas urbanas e industrializadas.

\section{CONCLUSÕES}

Os efeitos que uma seca pode causar dependem, em grande parcela, da capacidade de organização e enfrentamento da sociedade. A análise do capital hidráulico cearense acumulado ao longo do tempo evidencia como foi possível a transição de uma sociedade frágil, dependente da ocorrência de chuvas, para uma sociedade hidráulica, que se expandiu em uma região semiárida com grande limitação de recursos hídricos. As lições aprendidas com as secas passadas contribuíram para a formalização da compreensão estatal sobre os impactos da seca, e da necessidade de intervenção governamental. Outra importante lição encontrada quando visitada a História foi que os impactos da seca são mais profundos diante da ausência das ações governamentais, e mais, das decisões equivocadas, como os campos de concentração para os flagelados das secas de 1915, 1919 e 1932 por exemplo, que causaram milhares de mortes sob a tutela do Estado; e ainda quando a seca foi utilizada como instrumento de interesses políticos. Neste contexto, a pior seca é a seca política, quando os impactos da seca são aprofundados pela ação política ou ausência dela, que transforma um evento natural crítico em uma oportunidade de articular interesses políticos eleitoreiros, como registra a História. 
Se a principal solução hidráulica foi a açudagem, que lança a sociedade das chuvas para a civilização hidráulica, ela, a açudagem, exibe limitações quanto a sua eficácia para a convivência com as secas dos diferentes setores da sociedade. Por exemplo, entre 2012 e 2017, o mais longo período com precipitações abaixo da média, o município de Fortaleza com mais de 2,5 milhões de habitantes e o Complexo Industrial e Portuário do Pecém se mantiveram abastecidos graças aos açudes e sistemas de transposição de águas.

No entanto, os benefícios do capital hidráulico não se apresentam na mesma medida para outros setores da sociedade cearense. Na zona rural, o abastecimento ainda é muito impactado quando da ocorrência de eventos de seca, como pôde ser constatado no mesmo período de 2012 a 2017, quando quase R \$ 150 milhões foram gastos em média por ano para abastecimento de água via carros-pipa, o que se verificou em 78\% dos municípios cearense em média. Apesar do desafio técnico e econômico de abastecimento no meio rural, o que se observa também em outras regiões partes do mundo, é preciso reconhecer que o capital hidráulico adquirido também promoveu melhores condições de convivência com as secas no meio rural no Ceará, uma vez que os açudes servem de fonte hídrica mesmo para o abastecimento através de carros-pipa.

Alguns questionamentos também surgem com o presente trabalho: Como se pode equalizar um sistema de abastecimento, distribuído entre metrópole e sertão, enquanto os sertanejos têm entre seu capital hidráulico um comboio de carros pipas, e o atendimento da metrópole é reforçado por transposição de bacias hidrográficas? Como é possível pensar um sistema nitidamente em dicotomia, em que os sertanejos são apoiados em pequenos açudes e cisternas enquanto o meio urbano divide suas águas com grandes consumidores do setor industrial? 0 grande desafio parece ser a distribuição do bônus do capital hidráulico para toda a sociedade cearense.

\section{REFERÊNCIAS}

Abreu, C. (1998). Capítulos de história colonial: 1500-1800. Brasília: Conselho Editorial do Senado Federal.

Agência Nacional de Águas - ANA. (2018). Sistema de informações hidrológicas. Recuperado em 10 de junho de 2020, de www.snirh.gov.br/hidroweb

Albuquerque, E. L. S., Souza, M. J. N., Medeiros, C. N., Sousa, F. J., \& Lima, K. A. (2014). Perfil geossocioeconômico: um olhar para as Macrorregiões de Planejamento do estado do Ceará. Fortaleza: IPECE.

Azevedo, L. G. T., Porto, R. L., Méllo Junior, A. V., Pereira, J. G., Arrobas, D. P., \& Noronha, L. C. P. (2005). Transferência de água entre bacias hidrográficas. Brasília: Banco Mundial.

Braga, R. (1947). Um capítulo esquecido da economia pastoril do Nordeste. Revista do Instituto do Ceará.

Brasil Neto, L. G. (2019). Condutas administrativas de controle para prevenção dos crimes cometidos no âmbito da Operação Carro-Pipa. Revista Controle - Doutrina e Artigos, 17.

Brasil, P., \& Medeiros, P. H. A. (2020). NeStRes - model for operation of Non-Strategic Reservoirs for irrigation in drylands: model description and application to a semiarid basin. Water Resources Management, 34, 195-210.

Campos, J. N. B. (2014). Secas e políticas públicas no semiárido: ideias, pensadores e períodos. Estudos Avançados, 28.

Ceará. Governo do Estado. Secretaria dos Recursos Hídricos - SRH. (2019). Atlas Eletrônico da Secretaria de Recursos Hídricos do Ceará - SRH. Recuperado em 10 de junho de 2020, de http://atlas.srh.ce.gov.br/

Companhia de Gestão dos Recursos Hídricos do Ceará - COGERH. (2019). Portal Hidrológico do Ceará. Companhia de Gestão dos Recursos Hídricos do Ceará. Recuperado em 10 de junho de 2020, de http://www.hidro.ce.gov.br/

de Araújo, J. C., \& Bronstert, A. (2016). A method to assess hydrological drought in semiarid environments and its application to the Jaguaribe River basin, Brazil. Water International, 41, 213-230.

de Araújo, J. C., \& Medeiros, P. H. A. (2013). Impact of dense reservoir networks on water resources in semiarid environments. Australasian Journal of Water Resources, 17(1), 87-100.

de Menezes, A. B. (1901). Algumas origens do Ceará. Revista do Instituto do Ceará.

Fernandes, D. S., Heinemann, A. B., da Paz, R. L., Amorim, A. O., \& Cardoso, A. S. (2009). Índices para a quantificação da seca (Vol. 244). Embrapa Arroz e Feijão.

Furtado, C. (1987). Transformação e crise na economia mundial. São Paulo: Paz e Terra.

Girão, R. (2000). História econômica do Ceará. (2. ed.). Fortaleza: Casa José de Alencar.

Girão, V. C. (1984). As oficinas ou charqueadas no Ceará. Fortaleza: Secretaria de Cultura e Desporto. 
González, J. F., Decker, C., \& Hall, J. W. (2017). The economic impacts of droughts: A framework for analysis. Ecological Economics, 132, 196-204.

Guerra, P. B. (1981). A civilização da seca. Fortaleza: DNOCS.

Gutiérrez, A. P. A., Engle, N. L., Nys, E., Molejón, C., \& Martins, E. S. (2014). Drought preparedness in Brazil. Weather and Climate Extremes, 3, 95-106.

Instituto Brasileiro de Geografia e Estatística - IBGE. (2006). Estatísticas do século XX. Rio de Janeiro: IBGE.

Instituto Brasileiro de Geografia e Estatística - IBGE. (2011). Censo demográfico 2010. Rio de Janeiro: IBGE.

Jucá Neto, C. R. (2014). Primórdios da urbanização no Ceará. Fortaleza: Banco do Nordeste/UFC.

Medeiros, P. H. A., \& de Araújo, J. C. (2014). Temporal variability of rainfall in a semiarid environment in Brazil and its effect on sediment transport processes. Journal of Soils and Sediments, 14, 1216-1223.

Medeiros, P. H. A., \& Sivapalan, M. (2020). From hard-path to soft-path solutions: slow-fast dynamics of human adaptation to droughts in a water scarce environment. Hydrological Sciences Journal, 65(11), 1803-1814. http://dx.doi.org/10.1080/02626667.2020.1770258.

Medeiros, P. H. A., Güntner, A., Francke, T., Mamede, G., \& de Araújo, J. C. (2010). Modelling spatio-temporal patterns of sediment yield and connectivity in a semi-arid catchment with the WASA-SED model. Hydrological Sciences Journal, 55, 636-648.

Mishra, A. K., \& Singh, V. P. (2010). A review of drought concepts. Journal of Hydrology (Amsterdam), 391, 202-216.

Neves, F. C. (2007). A seca na história do Ceará. In S. Souza (Coord.), História do Ceará (4. ed.). Fortaleza: Fundação Demócrito Rocha.

Pereira, B. S., Medeiros, P. H. A., Francke, T., Ramalho, G. B., Foerster, S., \& de Araújo, J. C. (2019). Assessment of the geometry and volumes of small surface water reservoirs in a semiarid region with high reservoir density by remote sensing. Hydrological Sciences Journal, 64(1), 66-79.

Ponte, S. R. (2001). Fortaleza da Belle Époque: reforma urbana e controle social (1860-1930) (3. ed.). Fortaleza: Fundação Demócrito Rocha.

Rabelo, U. P., \& Lima Neto, I. E. (2018). Efeito de secas prolongadas nos recursos hídricos de uma região semiárida: uma análise comparativa para o Ceará. Revista DAE, 66, 61-79.

Rêgo, T. C. C. C. (2008). Proposta metodológica para gestão de secas: o caso da bacia do Alto Jaguaribe, Ceará. (Tese de doutorado). Universidade Federal do Ceará, Fortaleza.

Santos, M. (1999). A natureza do espaço: técnica e tempo; razão e emoção. São Paulo: Hucitec.

Sarmento, F. J. (2005). Transposição do Rio São Francisco - realidade e obra a construir. Brasília: EDICEL.

Schneider, S. H. (1996). Encyclopaedia of climate and weather. New York: Oxford University Press.

UN Secretariat General. (1994). United nations convention to combat drought and desertification in countries experiencing serious droughts and/or desertification, particularly in Africa. Paris.

Secreto, M. V. (2007, julho-dezembro). A ocupação dos "espaços vazios" no governo Vargas: do "Discurso do rio Amazonas" à saga dos soldados da borracha. Estudos Históricos, 40.

Silva, F. J. A., Araújo, A. L., \& Souza, R. O. (2007). Águas subterrâneas no Ceará - poços instalados e salinidade. Revista Tecnologia, 28(2), 136-159.

Teófilo, R. (1922). A fome: cenas da seca no Ceará. Rio de Janeiro: Imprensa inglesa.

Wilhite, D. A. (2000). Drought as a natural hazard: concepts and definitions. In D. A. Wilhite (Ed.), Droughts: global assessment. London: Routledge. 